\title{
ANL/ED/CP--85853
}

Conf- $950311--3$

\section{Failed Fuel Monitoring and Surveillance Techniques for Liquid Metal Cooled Fast Reactors*}

\author{
By \\ J. D. B. Lambert, R. Mikaili, K. C. Gross, and R. V. Strain \\ Argonne National Laboratory \\ 9700 South Cass Avenue \\ Argonne, Illinois 60439, USA \\ and \\ T. Aoyama, S. Ukai, S. Nomura, and N. Nakae \\ Power Reactor \& Nuclear Fuel Development Corporation \\ Oarai Engineering Center \\ 4002 Narita, Oarai-machi, Ibaraki-ken, 311-13, JAPAN
}

Conference Proceedings

BNES Conference - Fuel Management and Fuel Handling

March 20-22, 1995

Edinburgh, United Kingdom

The submitted menuscript has been authored by
contractor of the U. S. Government under
contract No. W-31-109-ENG-38. Accordingly,
the U. S. Government retains a nonexclusive,
roy alty-free license to publish or reproduce the
published form of this contribution or allow
others to do so, for U. S. Government purposes.

*Work supported by the U. S. Department of Energy, Reactor Systems Development Technology, under Contract No. W-31-109-ENG-38. 


\section{DISCLAIMER}

This report was prepared as an account of work sponsored by an agency of the United States Government. Neither the United States Government nor any agency thereof, nor any of their employees, makes any warranty, express or implied, or assumes any legal liability or responsibility for the accuracy, completeness, or usefulness of any information, apparatus, product, or process disclosed, or represents that its use would not infringe privately owned rights. Reference herein to any specific commercial product, process, or service by trade name, trademark, manufacturer, or otherwise does not necessarily constitute or imply its endorsement, recommendation, or favoring by the United States Government or any agency thereof. The views and opinions of authors expressed herein do not necessarily state or reflect those of the United States Government or any agency thereof. 


\section{DISCLAIMER}

Portions of this document may be illegible in electronic image products. Images are produced from the best available original document. 


\title{
Failed Fuel Monitoring and Surveillance Techniques for Liquid Metal Cooled Fast Reactors
}

\author{
J. D. B. Lambert, R. Mikaili, K. C. Gross, and R. V. Strain \\ Argonne National Laboratory \\ 9700 South Cass Avenue \\ Argonne, Illinois 60439, USA
}

\author{
T. Aoyama, S. Ukai, S. Nomura, and N. Nakae \\ Power Reactor \& Nuclear Fuel Development Corporation \\ Oarai Engineering Center \\ 4002 Narita, Oarai-machi, Ibaraki-ken, 311-13, Japan
}

Introduction

The Experimental Breeder Reactor II (EBR-II) has been used as a facility for irradiation of LMR fuels and components for thirty years. "During this time many tests of experimental fuel were contimed to cladding breach in order to study modes of element failure; the methods used to identify such failures are described in a parallel paper [1]. This paper summarizes experience of monitoring the delayed-neutron (DN) and fission-gas (FG) release behavior of a smaller number of elements that continued operation in the "run-beyond-cladding-breach" (RBCB) mode. The scope of RBCB testing, the methods developed to characterize failures on-line, and examples of DN/FG behavior are described. Not covered are the results of post-irradiation examination of the test elements, which have been reported elsewhere [2-5].

Scope of Oxide RBCB Testing in EBR-II

When a chance fuel failure occurs in a commercial LMR, it was always argued that reactor operation should continue to a scheduled refueling, much as it does in an LWR: to shutdown immediately and remove the failure would be probably unnecessary and not economic. But continued operation would require assurance that degradation of the $(\mathrm{U}, \mathrm{Pu}) \mathrm{O}_{2}$ element due to formation of fuel-sodium reaction product, or FSRP [5], was slow and monitorable, and that contamination from loss of fuel or fission products woukd not seriously impact the operation and maintenance of the reactor.

The three issues of element stability, monitorability, and release of contamination during failed fuel operation thus became the focus of an RBCB program in support of the Clinch River Breeder Reactor (CRBR) [6]. From 1981 RBCB testing continued in the broader context of a twophase collaboration between the U.S. Department of Energy and the Power Reactor and Nuclear Fuel Development Corporation of Japan. The collaboration is due to end in 1995 with the completion of Phase II test examinations.

*Note: EBR-II was put into a "hot standby" status on September 30, 1994, prior to permanent shutdown.

Phase I Tests (1978-86)

The eighteen Phase I tests were in four categories (Table 1) with differing objectives. Fifteen tests employed elements of the basic CRBR design: $86 \%$ smear density, $\left(\mathrm{U}_{0.75} \mathrm{Pu}_{0.25}\right)_{\mathrm{O}_{2}}$ pellets in 0.38-mm thick, 5.84-mm external diameter, $20 \%$-cold worked 316 or D9 stainless steel cladding; external diameters were larger in the XY-2, V4 and V5 tests.

Table 1 Phase I RBCB Program in EBR-II

\begin{tabular}{|c|c|c|c|}
\hline Category & Test & Time* & Description \\
\hline Scoping Tests & $\begin{array}{l}1 \\
2 \\
3 \\
X Y-2\end{array}$ & $\begin{array}{r}5.5 \\
14.5 \\
21.5 \\
6.5\end{array}$ & $\begin{array}{l}\text { End-of-life (EOL) } \\
\text { failures } \\
\text { Midlife (MOL) } \\
\text { failure under } \\
\text { BFTF*** }\end{array}$ \\
\hline $\begin{array}{l}\text { Kinetics \& } \\
\text { Contamination } \\
\text { Tests Under } \\
\text { BFTF }\end{array}$ & $\begin{array}{l}\text { K1 } \\
\text { K2A } \\
\text { TOPI-2 } \\
\text { K2B } \\
\text { K2C }\end{array}$ & $\begin{array}{r}97 \\
6 \\
3 \\
111 \\
22\end{array}$ & $\begin{array}{l}\text { Natural EOL } \\
\text { Induced MOL } \\
\mathrm{K} 2 \mathrm{~A}+15 \% \text { TOP } \\
\text { Long-term K2A } \\
\mathrm{K} 2 \mathrm{~A} \text { at high } \\
\text { temperature }\end{array}$ \\
\hline $\begin{array}{l}\text { Irradiation/ } \\
\text { Fabrication } \\
\text { Variables } \\
\text { Tests }\end{array}$ & $\begin{array}{l}\text { V2 } \\
\text { V4 } \\
\text { V5 } \\
\text { V6 } \\
\text { V7A } \\
\text { B, C }\end{array}$ & $\begin{array}{r}152 * * \\
6 \\
150 \\
147 \\
5 \\
5,0\end{array}$ & $\begin{array}{l}\text { Weld failures } \\
7.37-\mathrm{mm} \text { elements } \\
13.2-\mathrm{mm} \text { blankets } \\
\text { BFTF bundle test } \\
\text { Effects of storage } \\
\text { in } 370^{\circ} \mathrm{C} \text { sodium }\end{array}$ \\
\hline
\end{tabular}

DN/FG D1 $45 \quad$ Power changes

Behavior Tests D2 $9.5 \quad$ In situ $15 \%$ TOP Under BFTF

*Full power days with

DN signal

**FG leaker only
***BFTF: Breached Fuel Test Facility with dedicated DN monitor 
Nine tests were performed under the breached fuel test facility (BFTF) to allow independent monitoring of delayedneutron (DN) signals [7]; seven BFTF tests contained deposition samplers for post-test measurement of fuel and fission product loss. The D2 and TOPI-2 tests included a $15 \%$ transient overpower (TOP). The early scoping tests were performed with natural end-of-life or midlife faihures [2]. The remaining tests involved elements either with defects through the cladding wall (V2, V5 and V7), or with locally prethinned cladding and small plenums that caused failure at midlife.

Elements operated at $25-40 \mathrm{~kW} / \mathrm{m}$ and peak cladding temperatures were generally $550-700^{\circ} \mathrm{C}$, although $\mathrm{K} 2 \mathrm{C}$ elements inadvertently operated at peak values near $800^{\circ} \mathrm{C}$ [8]. Operating time with a $D N$ signal ranged from 5.5 days for RBCB-1 with an EOL failure to 150 days for simulated blanket-rod failures (V5); the number of shutdown/startup cycles was larger than in a commercial reactor and a maximum of ten for the V6 test. Phase I test results were reported to the BNES in 1990 [3].

\section{Phase II Tests (1987-94)}

The Phase II program has involved sixteen tests in four areas (Table 2): (i) improvements in monitoring failed fuel, using mostly BFTF tests; (ii) the thermal impact of FSRP formation in 7.5-mm diameter elements, especially on power-to-melt (PTM) values; (iii) the effects of storing breached elements in hot $\left(\sim 500^{\circ} \mathrm{C}\right)$ sodium; and (iv) tests to show safe RBCB operation. Elements operated at linear powers as low as $5-10 \mathrm{~kW} / \mathrm{m}$ in the $\mathrm{S} 1$ test and as high as 55 $\mathrm{kW} / \mathrm{m}$ in the B series PTM tests; maximum cladding temperatures were in the range of $550-650^{\circ} \mathrm{C}$.

The fission-product source (FPS) that occasionally was used to calibrate the DN/FG detectors contained $3.5 \mathrm{wt} . \%$ $\mathrm{U}-\mathrm{Ni}$ alloy tubing that comprised the walls of 13 flowthrough capsules in a BFTF subassembly; each capsule contained a driver fuel element to allow normal sodium flow (i.e., transit time) through the subassembly. The upgrade needing calibration in 1991 was installation of a triple-station DN detection system, whereby DN signals might be analyzed on-line (see a later discussion).

The A1-1 test used a K2A element which had become a gas leaker in that test. The A2-series tests used defected V6 elements in individual breached pin sampler capsules (BPSCs). The flow-through design of the BSPC had been developed to filter contaminants from $>95 \%$ of sodium flowing past a defected element; sodium velocity at the defect was a primary variable between tests. The A2-0 and A2-2 test elements had a 1.5-mm diameter hole drilled through to the central void to simulate the geometry which seemed to promote fuel loss in the center element in the overheated $\mathrm{K} 2 \mathrm{C}$ test [8]; the A2-1 elements had a hole through the cladding only.

The B-series elements were defected in the plenum region to allow entry of sodium in-reactor and to simulate defective welds. The symmetric FSRP layer that formed made for a clear interpretation of the impact of this material on element thermal performance; preliminary findings were reported in 1993 [5].
The S1 test contained a V6 and B1-1 element defected in the fuel column region with a $1.5-\mathrm{mm}$ diameter hole through the cladding. The elements were irradiated in a row 11 position at $5-10 \mathrm{~kW} / \mathrm{m}$ for approximately 250 days. The test simulated the storage of discharged failed fuel in the periphery of a commercial LMR where conditions combine a low fission density with hot $\left(\sim 500^{\circ} \mathrm{C}\right)$ sodium.

The $\mathrm{Cl}$ test simulated high burnup with an unusually tight 19-element bundle (pitch-to-diameter $\sim 1.11$ ). The center pin was prepressurized and had prethinned cladding at the core midplane to induce failure; the surrounding elements had small plemims to simulate high burnup. Failure occurred in the final two weeks of irradiation but caused no detectable DN signals; the test has not yet been examined. The C2 test elements did not experience failure.

Table 2 Phase II RBCB Program in EBR-II

\begin{tabular}{|c|c|c|c|}
\hline Category & Test & At. $\%^{*}$ & Description \\
\hline $\begin{array}{l}\text { DN Signal } \\
\text { Behavior/Fuel } \\
\text { Loss Tests }\end{array}$ & FPS & Low & $\begin{array}{l}\text { U-Ni source to } \\
\text { calibrate } \mathrm{DN} / \mathrm{FG} \\
\text { detectors }\end{array}$ \\
\hline Under BFTF & $\begin{array}{l}\text { A1-1 } \\
\text { A2-0 }\end{array}$ & $\begin{array}{l}5 \\
10\end{array}$ & $\begin{array}{l}\text { K2A MOL faihure } \\
\text { V6 element drilled } \\
\text { to central void in } \\
\text { open-core BPSC** }\end{array}$ \\
\hline & A2-1 & 10 & $\begin{array}{l}\text { Two defected V6 } \\
\text { elements in BPSCs }\end{array}$ \\
\hline & A2-2 & 10 & $\begin{array}{l}\text { V6 element drilled to } \\
\text { central yoid in BPSC }\end{array}$ \\
\hline $\begin{array}{l}\text { Thermal } \\
\text { Evaluation }\end{array}$ & B1-1,2 & 5 & $\begin{array}{l}\text { Test element } \\
\text { pre-irradiation }\end{array}$ \\
\hline Tests & $\begin{array}{l}\text { B1-3 } \\
\text { B1-4 } \\
\text { B1-5 } \\
\text { B1-6 } \\
\text { B1-7 } \\
\text { B2 }\end{array}$ & $\begin{array}{l}0 \\
0 \\
0 \\
5 \\
5 \\
5\end{array}$ & $\begin{array}{l}\text { Power-to-melt } \\
\text { Short-term RBCB } \\
\text { Long-term RBCB } \\
\text { Long-term RBCB } \\
\text { Power-to-melt } \\
\text { Transient B1-7 }\end{array}$ \\
\hline $\begin{array}{l}\text { "Hot Storage" } \\
\text { Test }\end{array}$ & S1 & 5,10 & $\begin{array}{l}\text { Defected V6 and B1 } \\
\text { elements in blanket } \\
\text { region }\end{array}$ \\
\hline
\end{tabular}

\begin{tabular}{|c|c|c|c|}
\hline $\begin{array}{l}\text { Safe RBCB } \\
\text { Operation }\end{array}$ & $\mathrm{C} 1$ & $<10$ & $\begin{array}{l}\text { RBCB in simulated } \\
\text { high-burnup bundle }\end{array}$ \\
\hline Tests & $\mathrm{C} 2$ & 5 & Advanced cladding \\
\hline
\end{tabular}

Monitoring Fuel Failures at EBR-M

The systems installed at EBR-II to detect fuel failures are described fully in a parallel paper [1] and are only touched on here. Described now are the techniques which were developed in an effort to obtain more information than simply the DN-signal level of an RBCB element, or the activity it produced in the EBR-II cover gas. Although analysis was generally performed long after events in-reactor 
using archive data tapes, the intent always has been to develop on-line methods to aid reactor operators.

\section{Delayed-Neutron (DN) Signal Anatyses}

The activities of DN precursors released to sodium are measured by the Fuel Element Rupture Detector (FERD) in a bypass loop that obtains sodium from the outlet of the intermediate heat exchanger (IHX). The transit time from the core to the $\mathrm{BF}_{3}$ detectors is $\sim 18 \mathrm{~s}$, comprising 12-13 $\mathrm{s}$ from the failure in-core to the inlet of the FERD loop, and $\sim 5 \mathrm{~s}$ in the loop itself. Early on in the program we realized that this transit time could be increased systematically in a FERD flow reduction (FFR) test in order to determine the hold-up time $\left(T_{h}\right)$ and the equivalent recoil area (ERA) of a failure [9]. It was hoped that a change in either parameter could be used to quantitatively monitor the condition of an RBCB element.

Valid FFR results were obtained when DN signals did not vary appreciably during the tests, which last one hour. In practice, DN signals were found to be high and variable when FSRP was being formed in the early dynamic stages of RBCB operation, and during later power maneuvers, especially reactor startups. Thus FFR tests were generally applicable only when a cladding breach had been stabilized by FSRP formation. When performed, however, FFR tests did indicate significant precursor aging $\left(T_{h}<30 s\right)$ and ERA values that consistently were many times the final geometric area of a breach [3]. This increased sensitivity of DN signal, sometimes referred to as the " $k$ " factor, where $k \sim 100$ [10], was attributed to release mechanisms that were in addition to simple recoil. For example, Fig. 1 shows the steady DN signals that indicated a stable breach in the D1 test. The dips that appear in the FERD signals corresponded with FFR tests: they gave ERA values that gradually declined from 47 to $31 \mathrm{~cm}^{2}$ and $T_{h}$ vahues of a few seconds. Such values were consistent with a diffusional release of $\mathrm{I}$ and $\mathrm{Br}$ precursors provided that the diffusion coefficients were $10^{-5}$ to $10^{-6} \mathrm{~cm}^{2} / \mathrm{s}$ [11]. A model for the behavior of RBCB elements which is based on the observed extent of FSRP formation and this diffusional release of DN precursors has been described elsewhere [12].

Triple-station DN detection was devised for Phase II tests as a means of obtaining $T_{h}$ and ERA values without the need to alter sodium flow and even when DN signals were varying [13]. In the basic concept detectors are strung along the path of the main coolant so that precursors are naturally aged from one detector to the next. In retrofitting the system to EBR-II, the places where new detectors could be located easily-near the upper end of the Z-shaped sodium exit pipe from the core, and near the top and bottom of the IHX-were found to have a higher flux of prompt neutrons escaping from the core than DNs in the coolant flow. This unexpectedly high background was sufficient to obscure the DN signals from the FPS for all locations except near the Zpipe, a situation that could be avoided by design in a new reactor. Nevertheless, the FPS test that was intended to calibrate the new DN system did allow the determination of FG disengagement constants, as will be later explained.

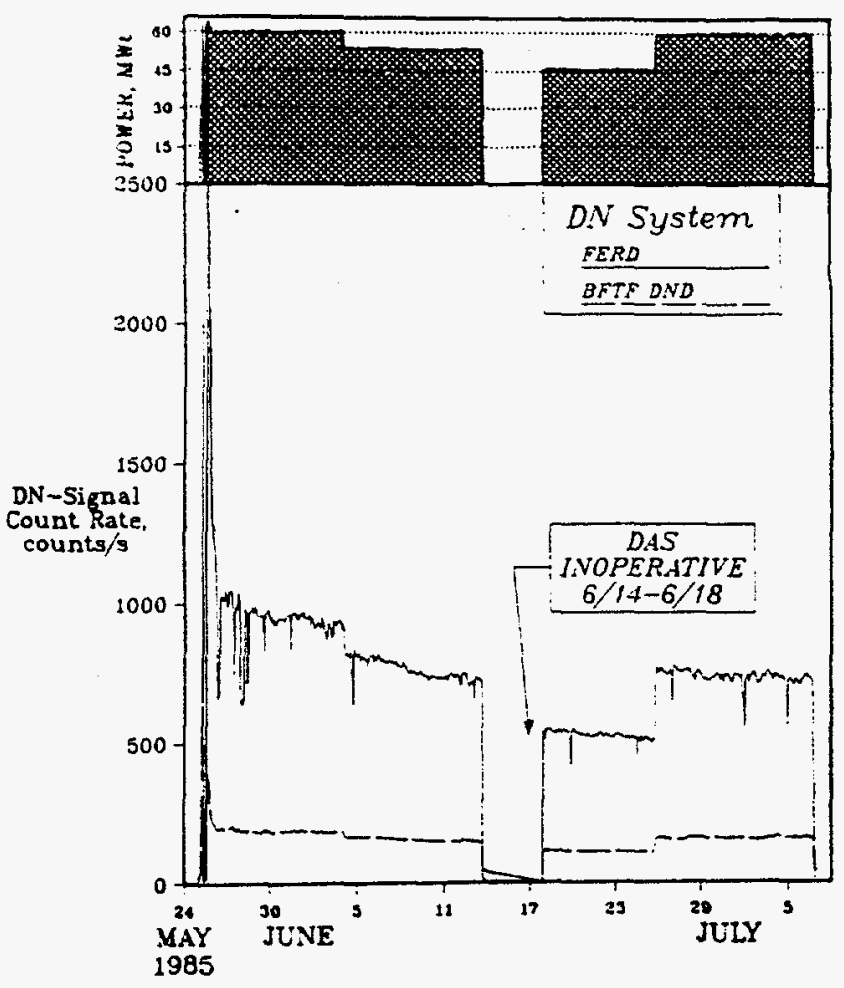

Fig. 1 Steady DN Signals at Various Power Levels During the D1 Test, Indicating a Stable Breach

Double-station DN monitoring was available for all tests run under the BFTF, with transit times of $\sim 5 \mathrm{~s}$ and $\sim 28 \mathrm{~s}$ to the BFTF and FERD detectors, respectively. In practice, the different detectors, counting efficiencies and hydraulics of the two systems made meaningless any parameter more complicated than a simple dimensionless age index, defined as the ratio of the FERD count rate to the BFTF count rate. A rising index was taken to indicate an increasing holdup, or aging, of DN precursors; and a falling index, a situation where the holdup was decreasing. Although test-to-test comparisons of age index were not possible because of different sodium leakage at the BFTF/subassembly interfaces, the variation with time of the age index in a given test was probably valid: in general, the index was found to increase at the beginning of RBCB operation (Fig. 2) and to become constant or decrease towards the end. This behavior was taken to mean that, initially, the formation of FSRP was lengthening or closing off escape paths for DN-precursor release from the exposed fuel; later, diffusion of precursors through the FSRP increased or became constant as the product stabilized.

\section{Fission Gas (FG) Analysis}

FG released from a failure mixes turbulently with sodium and is transported as atoms or very fine bubbles. These exit $\sim 13 \mathrm{~s}$ later from the IHX into the primary tank and rise $\sim 3 \mathrm{~m}$ to the sodium surface, where they disengage and disperse rapidly in the $25-\mathrm{m}^{3}$ argon cover gas. Activities are measured $\sim 10 \mathrm{~min}$. later by the Ge-Li Argon Scanning System (GLASS) [14]. A small but persistent leakage of 

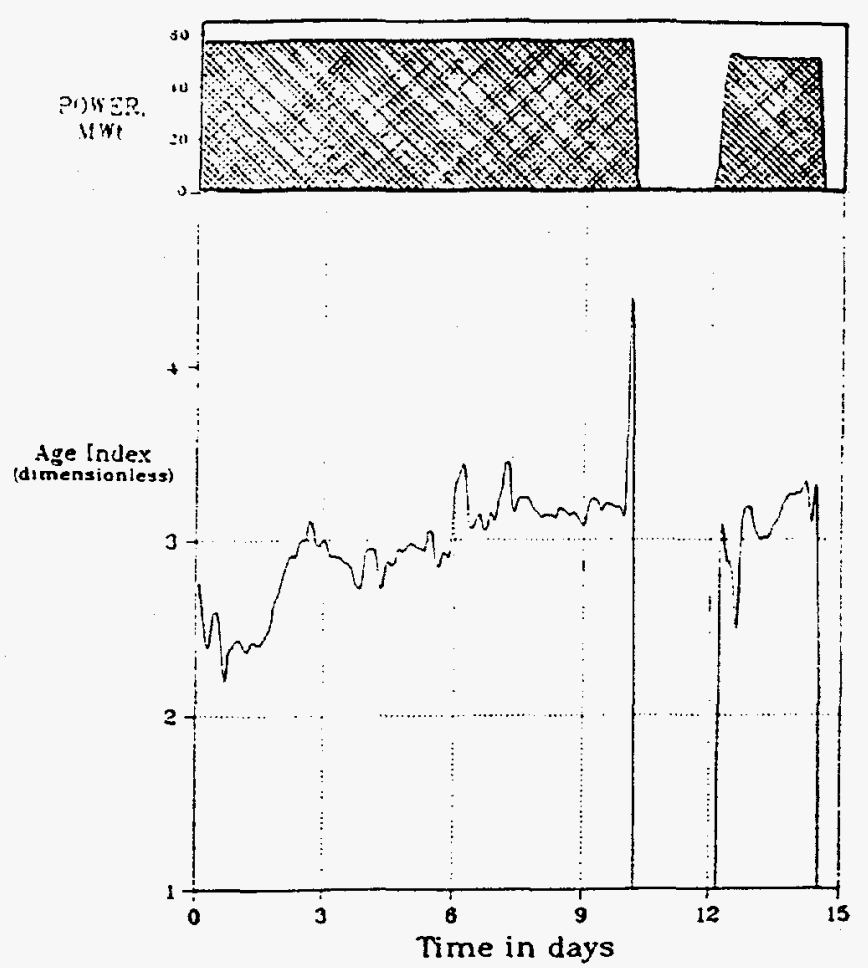

Fig. 2 Age Index at Beginning of K2B Test Indicating Increasing Age of DN Precursors

argon to the containment building requires that a cryogenic cleamup system (CGCS) [15] be used to purge the cover gas of activity during RBCB tests.

Analysis has been driven by the hope that the way FG is released from a failure, as deduced from measured covergas activities, and how release changes with time, could be used to help monitor the condition of an RBCB element. Only three or four modes of release seem likely: instantaneous recoil (and possibly knockout) from the surface of exposed fuel or FSRP; fast, pressure-driven release of stored gas from internal spaces; and slower diffusional release from the fuel/FSRP itself. Each mode has a distinct release-to-birth relationship [16]:

$R_{i} / B_{i}=k \cdot S \cdot L_{i} \cdot d /\left(4 W_{j}\right)$

for direct recoil release;

$R_{i} / B_{i}=\lambda_{i} \cdot\left(\left[1-\exp \left(-\lambda_{i} t\right)\right] / \lambda_{i}\right)$

for stored gas release; and

$R_{i} / B_{i}=3 \cdot\left[D_{i} /\left(\lambda_{i} a^{2}\right)\right]^{1 / 2}$

for diffusional release; where: $\lambda_{e}=$ Effective escape rate coefficient $\left(s^{-1}\right)$,

$t \quad=$ Irradiation time (s),

$D_{i}=$ Diffusion coefficient $\left(\mathrm{cm}^{2} / \mathrm{s}\right)$,

$a=$ Radius of the equivalent sphere of fuel $(\mathrm{cm})$,

$\mathbf{k}=$ Enhancement factor (dimensionless),

$S=$ Geometric defect area $\left(\mathrm{cm}^{2}\right)$,

$L_{i} \quad=$ Recoil range of $i$ th species $(\mathrm{cm})$,

$d=$ Density of fissile material $\left(\mathrm{g} / \mathrm{cm}^{3}\right)$, and

$W_{j}=$ Mass of $\mathrm{j}$-th fissile isotope $(\mathrm{g})$.

In theory, the dominant mode of release for active FG species could be identified from the slope of a curve of $\log$ $\left(R_{i} / B_{i}\right)$ versus $\log \left(\lambda_{i}\right)$ : from Eqs. (1-3) a slope of zero would indicate recoil release; a slope of -1 , stored gas release; and a slope of $-1 / 2$, diffusional release. In practice, an isotope activity $C_{i}$ measured in the cover gas must be related to a release rate $R_{i}$ in-reactor. That is, account must be taken for transport of gas in sodium, its disengagement to the cover gas, and operation of the CGCS to control activity. Nomura and others [17] derived $R_{i}$ in terms of parameters which either were known, measured, or could be calculated; they found:

$$
\begin{aligned}
R_{i}= & 37 V\left\{\left(1 / \lambda_{i}\right) \cdot d C_{i}^{*} / d t+C_{i}^{*} \cdot\left(\lambda_{i}+\lambda_{L}\right) / \lambda_{i}\right] \\
& {\left[\left(\lambda_{i}+\lambda_{d}\right) / \lambda_{d}\right] }
\end{aligned}
$$

for ${ }^{85 \mathrm{~m}} \mathrm{Kr},{ }^{87} \mathrm{Kr},{ }^{88} \mathrm{Kr}$, ${ }^{135 \mathrm{~m}} \mathrm{Xe}$, and ${ }^{138} \mathrm{Xe}$; and

$\begin{aligned} R_{i}= & 37 V\left[\left(1 / \lambda_{i}\right) \cdot d C_{i}^{*} / d t+C_{i}^{*} \cdot\left(\lambda_{i}+\lambda_{L}\right) / \lambda_{i}-C_{2}^{*} \cdot\left(\rho \lambda_{i-1}\right) / \lambda_{i}\right] . \\ & {\left[\left(\lambda_{i}+\lambda_{d}\right) / \lambda_{d}\right], }\end{aligned}$

for ${ }^{133} \mathrm{Xe}$ and ${ }^{135} \mathrm{Xe}$, where:

$\lambda_{i}=$ Decay constant for $\mathrm{i}$-th isotope $\left(s^{-1}\right)$,

$\lambda_{d}=$ Disengagement rate constant $\left(s^{-1}\right)$,

$\lambda_{L}=$ Cover gas leak rate constant $\left(s^{-1}\right)$,

$V=$ Cover gas volume $\left(\mathrm{cm}^{3}\right)$,

$d C_{i}^{*}=$ Activity difference of $i$-th isotope at time interval $\mathrm{dt}$ for no purging $(\mathrm{nCi} / \mathrm{mL})$, and

$f=$ Branching ratio.

The birth rate $B_{i}$ of the $i-$ th isotope is given by:

$B_{i}=Y_{i j} \cdot F_{j} \cdot W_{j}$,

where:

$Y_{i j}=$ Cumulative yield of $\mathrm{i}$-th isotope for fission of $j$-th fissile isotope,

$F_{j}=$ Specific fission rate for $\mathrm{j}$-th fissile isotope $\left(s^{-1} g^{-1}\right)$, and

$W_{j}=$ Mass of $\mathrm{j}$-th fissile isotope $(g)$.

In these equations, $\lambda_{i}, f, Y_{i j}, F_{j}, W_{j}$ are known, and $\lambda_{2}$ and $d C_{i}^{*}$ are obtained from the argon makeup rate and measured activities under purge conditions [17], respectively. The disengagement constant $\lambda_{d}$ is a crucial parameter and is derived from activities measured from a known source 
(an FPS) in-reactor. The same $\lambda_{d}$ value of $1.5 \cdot 10^{-5} \mathrm{~s}^{-1}$ was assumed for all FG isotopes in Ref. 17. In the 1991 FPS test, measured and predicted activities were found to agree more closely when different $\lambda_{d}$ values were used for the different FG isotopes. Figure 3 shows the excellent fits obtained for the longest and shortest half-life FG isotopes, using values of $\lambda_{d}{ }^{133}=2.1 \cdot 10^{-5} \mathrm{~s}^{-1}$ and $\lambda_{\mathrm{d}}{ }^{138}=2.9 \cdot 10^{-5} \mathrm{~s}^{-1}$. The FGAS code, which was devised to solve Eqs. (4-6), is now considered to be fully calibrated.

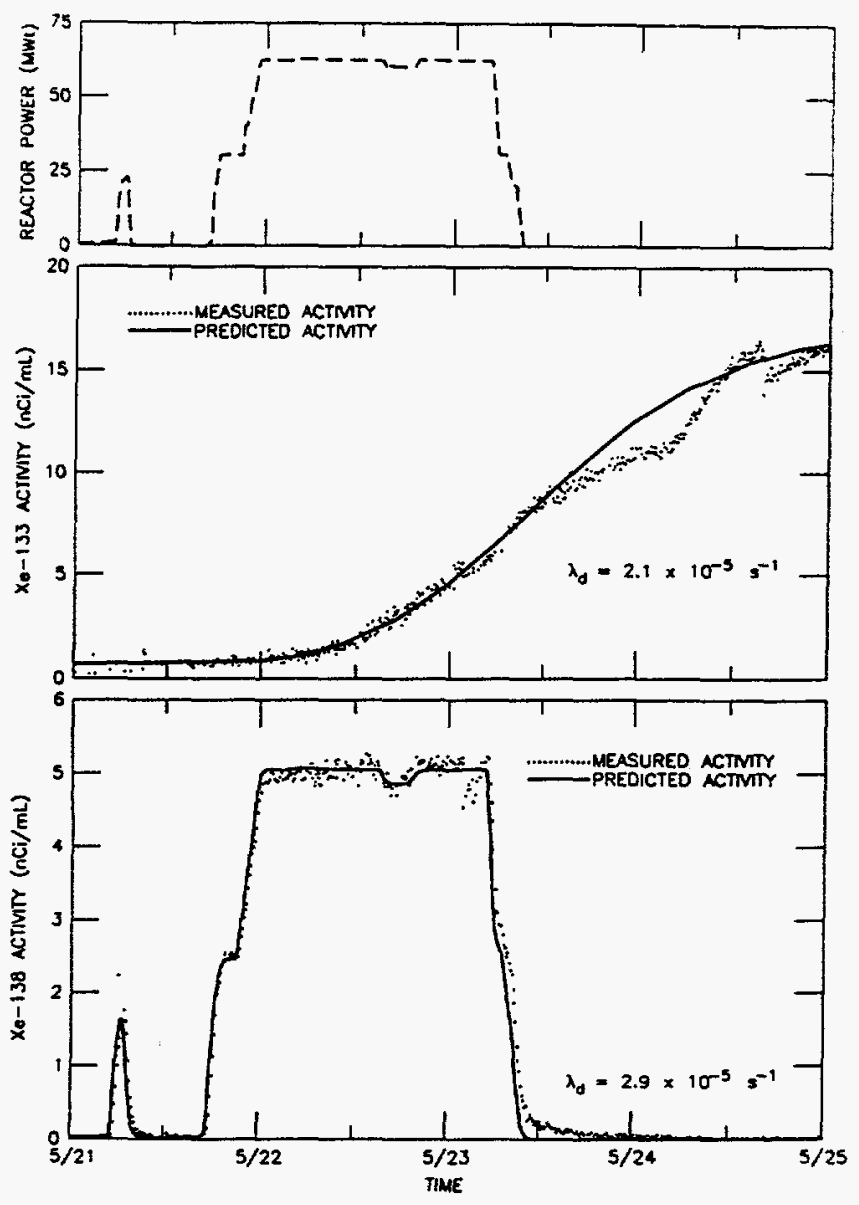

Fig. 3 Measured and Predicted $\mathrm{Xe}^{133}$ and $\mathrm{Xe}^{138}$ Activities for FPS for Different $\lambda_{d}$ Values

\section{Results of $R / B$ Analysis}

The remainder of this paper describes results of FGAS calculations of the release behavior of Phase I and Phase II tests. In general, FG release was found to be never by one mechanism, as determined by the slope of $\log \left(R_{i} / B_{i}\right)$ versus $\log \left(\lambda_{i}\right)$. Such behavior is to be expected: all release mechanisms will be operative to some extent, so that the dominant one will not have the exact functional relationship indicated by Eqs. (1-3). Despite this general fuzziness, there were three distinct R/B "signatures"; they were for: (i) plenum-defective elements which simulated upper weld defects; (ii) stable fuel-column failures; and (iii) fuel-column failures with detectable fuel loss.

\section{Plenum-Defective Elements}

Figure 4 shows the R/B behavior for the Phase I V2 test and the Phase II Bl-6 test; both tests contained defected elements in which sodium had entered and reacted uniformly with fuel; neither test gave detectable DN signals. The RB slopes were near -1.0 in both tests, suggesting release of stored long-lived gas. The B1-6 test exhibited a more dynamic behavior than the V2 test with $R / B$ slopes that exceeded -1.0. FG release then may have been via a fuelcladding gap which was partly filled with FSRP, because release for that geometry can exhibit an $R / B$ dependency of $\lambda^{-3 / 2}[18]$

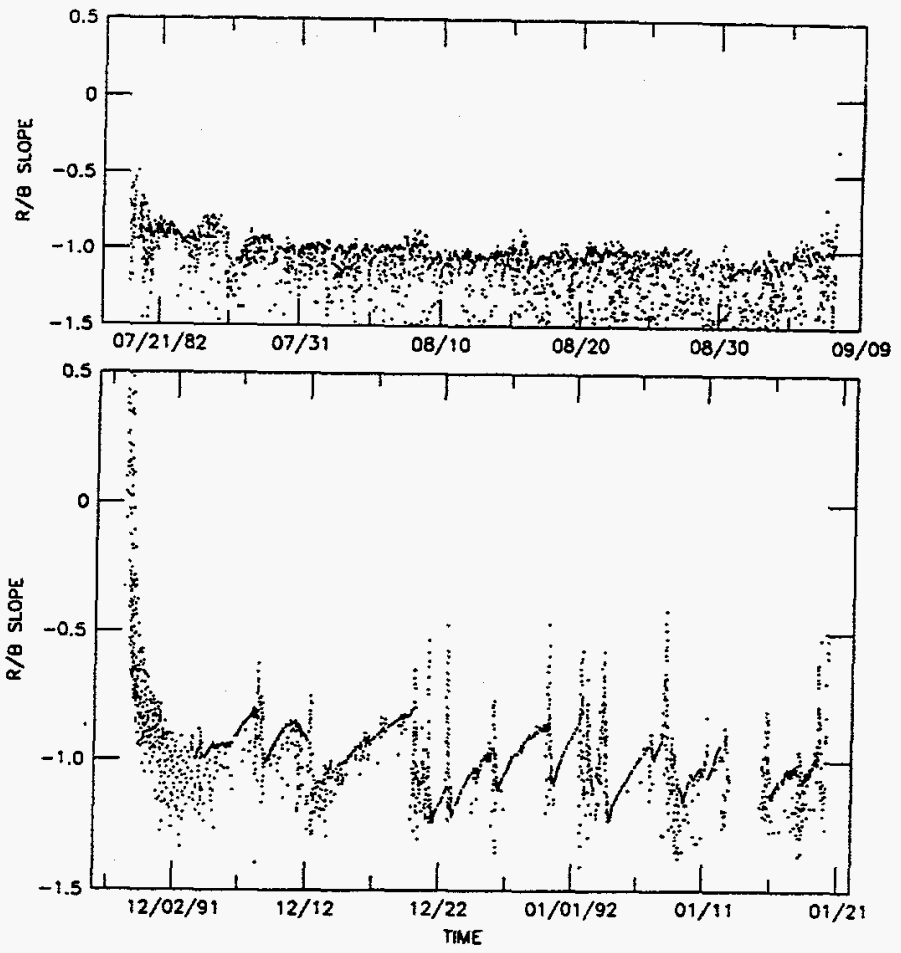

Fig. 4 R/B Behavior in Plenum-Defective Elements Upper: V2 Test Lower: B1-6 Test

\section{Benign Fuel-Column Failures}

Figure 5 shows the R/B behavior observed towards the end of the Phase I V6 test and the Phase II A1-1 test. Both tests were characterized by $R / B$ slopes between -0.6 and -0.8 , with vahues only slowly varying between these limits. This behavior is interpreted as being predominantly due to diffusional release of FG through a layer of FSRP. The 147-day V6 test exhibited occasional bursts of stored gas, presumably due to periodic venting of internal FG pressure by cracking of the FSRP. The figure inchudes DN signals for the V6 test: there appeared to be no particular correlation between minor changes observed in the R/B slope and either the FERD or BFTF signals. 

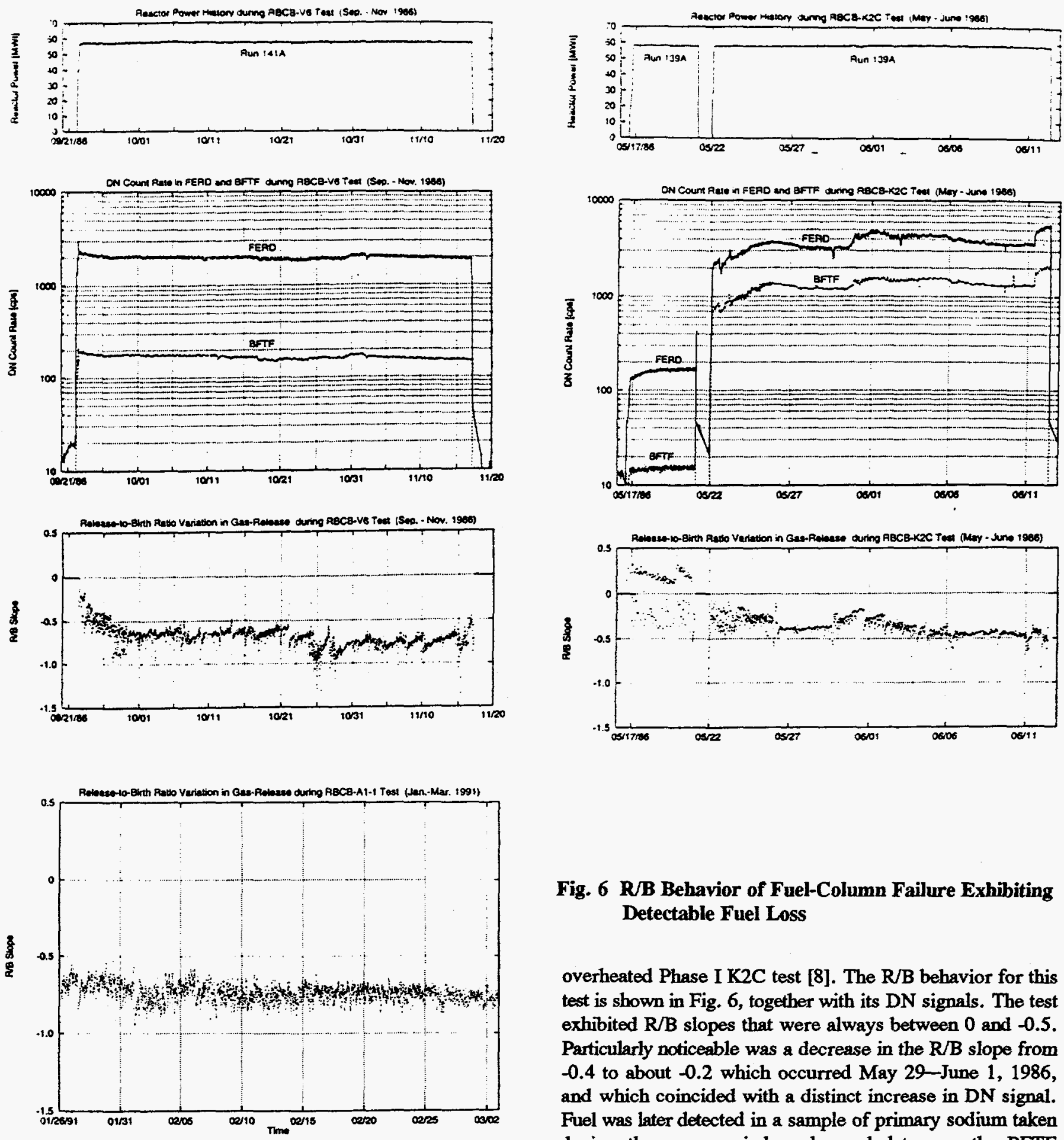

Fig. 6 R/B Behavior of Fuel-Column Failure Exhibiting Detectable Fuel Loss

overheated Phase I K2C test [8]. The R/B behavior for this test is shown in Fig. 6, together with its DN signals. The test exhibited R/B slopes that were always between 0 and -0.5 . Particularly noticeable was a decrease in the $R / B$ slope from -0.4 to about -0.2 which occurred May 29-June 1, 1986, and which coincided with a distinct increase in DN signal. Fuel was later detected in a sample of primary sodium taken during the same period, and, much later, on the BFTF deposition sampler.

That the mode of FG release showed a distinct change toward recoil over May 29-June 1 (1986) is considered significant: it marked the time when we believe that fuel was being lost from the central void of the center test element by vapor transport through a small breach of the cladding (Fig. 7), see Ref. 8 for further discussion. Such behavior was consistent with both the fuel and precursor species escaping directly from the surface of the central void with little or no holdup.

Some tests in the RBCB program are known to have released detectable amounts of fuel: one of them was the 


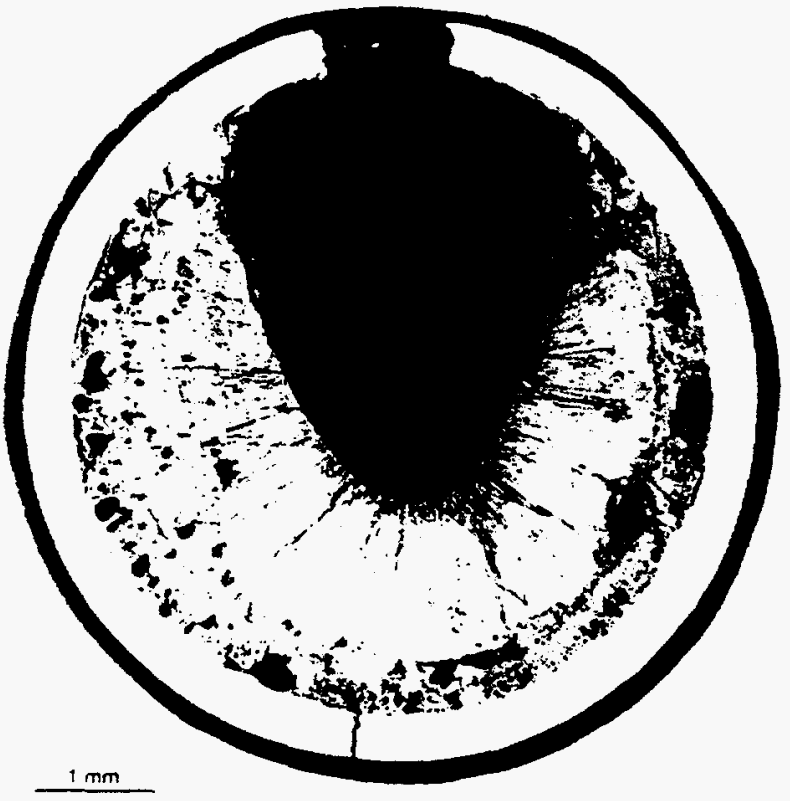

Fig. 7 Breach on Overheated K2C Test Element From Which Vapor Loss of Fuel Occurred

\section{Summary}

The RBCB program at EBR-II has shown that release of DN precursors and FG isotopes from mixed oxide elements curing $\mathrm{RBCB}$ operation involves a number of contributing factors. For example, due to enhanced release by diffusion, DN signals from a breach are always much larger than due to simple recoil, which makes for ready detection. Also signals tend to become steady after a few days to weeks, which implies a stabilization of the breach sites.

Release-to-birth (R/B) analysis of FG signals holds promise as a diagnostic tool. Simulated weld failures have had a distinct FG signature with $R / B$ values of -1.0 and gave no DN signals. Stable breaches with slowly varying DN signals seemed to release FG by diffusion and to exhibit characteristic $\mathrm{R} / \mathrm{B}$ values of -0.6 to -0.8 . Breaches that later were found to have lost fuel by vapor transport tended to exhibit high $D N$ signals and FG release by recoil, with $R / B$ values between 0 and -0.5 .

\section{Acknowledgments}

RBCB testing initially involved people from General Electric and Westinghouse Hanford Company, as well as colleagues in the EBR-II Division. The program then grew into a fruitful international collaboration of 14 years, principally between the Oarai Engineering Center (PNC) and Argonne National Laboratory. We must thank the very many individuals who made such an endeavor possible: the sheer number prechudes mentioning them by name, but their contributions are gratefully acknowledged.

This work was supported by the U.S. Department of Energy, Reactor Systems Development Technology, under Contract No. W-31-109-ENG-38.

\section{References}

1. J. D. B. Lambert al al., Failed Fuel Ldentification Techniques for Liquid Metal Cooled Reactors, this conference.

2. J. D. B. Lambert et al., Performance of Breached LMFBR Fuel Pins During Continued Operation, Proc. BNES Conf., Nuclear Fuel Performance, 1985, 1, 77.

3. J. D. B. Lambert et al., Run-Beyond-Cladding-Breach Oxide Testing in EBR-II, Proc. BNES Conf., Fast Reactor Core and Fuel Structural Behavior, 17-23, 1990.

4. R. V. Strain et al., Status of RBCB Testing of LMR Oxide Fuel in EBR-II, Proc. AESJ Conf., Fast Reactors and Related Fuel Cycles, 6.7-1 to 6.7-10, 1991.

5. R. V. Strain et al., Fuel-Sodium Reaction Product and Its Influence on Breached Mixed-Oxide Fuel Pins, J. Nuc. Mat., 204, 252-260, 1993.

6. D. F. Washburn et al., Mixed-Oxide Run-BeyondCladding-Breach Tests in EBR-II, Proc. ANS Conf., Fast Breeder Reactor Fuel Performance, 100-111, 1979.

7. R. H. Olp, The EBR-II Breached Fuel Test Facility, Proc. ANS. Conf., Fast, Thermal and Fusion Reactor Experiments, 1.296-306, 1982.

8. R. V. Strain et al., Behavior of Breached Mixed Oxide Fuel Pins during Off-Normal High-Temperature Operation, Nuc. Tech., 97, 227-240, 1992.

9. K. C. Gross and R. V. Strain, Delayed-Neutron Signal Characterization in a Fast Reactor, Nuc. Sci. \& Eng., 76, 163-174, 1980.

10. S. Jacobi et al., Core Surveillance of Liquid Metal Fast Breeder Reactors by Delayed Neutron Signals, Nuc. Sci. \& Eng., 100, 447-460, 1987.

11. S. Ukai et al., Release Characteristics of Delayed Neutron Precursors from a Breached FBR Element, J. Nuc. Sci. \& Tech., 26, 931-939, 1989.

12. S. Ukai et al., Development of Computer Code SAFFRON for Evaluating Breached Pin Performance in FBR's, J. Nuc. Sci. \& Tech., 31, 662-670, 1994.

13. K. C. Gross and R. V. Strain, Systems for On-Line Characterization of Delayed Neutron Signals, Trans. ANS, 47, 444, 1984.

14. G. S. Brunson, Monitoring Fission Gas in EBR-II by High Resolution GammaSpectrometry, Nuc. Tech., 25, 553-571, 1975.

15. L. R. Monson at al., The EBR-II Cover Gas Cleanup System, Proc. IAEA Symp., Design, Construction and Operating Experience of Demonstration LMFBRs, 465-475, 1978.

16. D. R. Olander, Fundamental Aspects of Nuclear Reactor Fuel Elements, 287-289, TDD-26711-p1 1976.

17. S. Nomura, K. C. Gross, and J. D. B. Lambert, Breached Pin Diagnosis by-Fission Gas Analysis in the EBR-II RBCB Program, Proc. ANS. Conf., Reliable Fuels for Liquid Metal Reactors, 6-105 to 6-118, 1986.

18. B. J. Lewis et al., Fuel Performance and Fission Product Relense Studies for Defected Fuel Elements, Nuc. Tech., 103, 220-245, 1993. 